\title{
Study on the Generation Mechanism and Development Law of the Zonal Disintegration in Deep Burial Tunnels
}

\author{
Xiaohui Ma, Jihong Wei $\mathbb{D}$, Jin Liu (D), Zezhuo Song, and Yuxia Bai \\ College of Earth Science and Engineering, Hohai University, Nanjing 210098, China \\ Correspondence should be addressed to Jihong Wei; weijhhhu@163.com
}

Received 27 August 2019; Revised 24 January 2020; Accepted 5 February 2020; Published 11 June 2020

Academic Editor: Dr Mahdi Mohammadpour

Copyright ( $\odot 2020$ Xiaohui Ma et al. This is an open access article distributed under the Creative Commons Attribution License, which permits unrestricted use, distribution, and reproduction in any medium, provided the original work is properly cited.

\begin{abstract}
In the development of underground spaces, we found that the mechanical properties of rock mass often demonstrate strong nonlinear characteristics. Some new phenomena emerge in deep rock mass engineering. This includes zonal disintegration and rock burst. Zonal disintegration is very important in deep tunnels. In this paper, we start with the mechanical properties of deep rocks to understand the preconditions for zonal disintegration. Using the Failure Approach Index (FAI), the process of zonal disintegration can be modeled by FLAC (FISH language). Our results indicate that tensile failure in the Supporting Pressure Zone (SPZ) is a precondition for zonal disintegration. Various factors that affect the generation of zonal disintegration are studied. When the maximum stress is in the axial direction, zonal disintegration will be present in deep tunnels. The high axial stress is necessary for zonal disintegration. We will present a zonal disintegration simulation in one coal mine for comparison with the borehole teleview data. We suggest some measures to prevent the development of zonal disintegration.
\end{abstract}

\section{Introduction}

The deep rock mass is situated in a unique environment with high stress, temperature, and water [1-3]. Zonal disintegration in this environment is important for stability, excavation, and design. This is analogue to shallow tunnel loose, plastic, and elastic zones [4-10]. Understanding the rock mechanical behaviors in this environment prevents the impact pressure in the excavation and blasting process. Many works in this regard have been carried out in the past. In the 1980s, Shemyakin et al. [11] have found out that the annular fractured zone with interval distribution appears in the face of excavation. The fracture zones of width $1.0 \sim 1.5 \mathrm{~m}$ often appear and their frequency depends on the stress. The shape of the fracture zone is similar to the shape of the tunnel. Using borehole periscope, Adams and Jager [12] have found that there are fractured zones of width $5 \sim 150 \mathrm{~mm}$ in Witwatersrand mining, South Africa. There is an intact rock zone of thickness about $1.0 \mathrm{~m}$ between interfracture zones. At the depth of $12 \mathrm{~m}$, fracture and nonfracture zones alternate. Malan and Spottiswoode [13] have studied the influence of time and excavation methods on zonal disintegration based on field monitoring. They found that the mine earthquake is a main factor for the development of zonal disintegration at the tunnel top. Metlov et al. [14] have simulated the process from elastic to failure using equilibrium thermodynamics theory. $\mathrm{Li}$ et al. [15] have discovered that zonal disintegration appears in the 6-1\# auxiliary tunnel in Jingping hydropower station from the elastic wave data. Fang [16] has studied the mechanical properties of surrounding rock by field test in Jingchuan and Zhangjiawa mines and he found that tensile and compressive zones appear alternatively. This alternative tensile and compressive pattern develops over time.

Sellers and Klerck [17] have investigated the influence of discontinuities on the alternative patterns of zonal disintegration. In deep tunnels by experimental methods, they have shown that the discontinuities are crucial for zonal disintegration. $\mathrm{Gu}$ et al. [18] have verified the existence of zonal disintegration by high compressive test on cylinder with circular and arch rectangular hollow shapes in the center. The results indicate that slip line failure appears near the tunnel wall and circular failure appears at the deep section for the circular tunnel. The slip failure appears at the 
top and bottom of the tunnel and layered failure appears in the sidewall for the arch rectangular tunnel. When the curvature of tunnel wall is big or the sidewall is high, it expands towards the free face under high axial pressure and layered failure appears. Qian [19] has pointed out that zonal disintegration happens when the initial stress is bigger than uniaxial compressive strength of the rock. The number of fractured zones depends on initial stress. Zonal disintegration appears more often with drill blasting than machine excavation. This is because zonal disintegration is dependent on unloaded process. Wang et al. [20] can predict the whole process of deformation and failure by static models based on a relationship between stress and volume change. Layer failure will first appear, then a "new" tunnel is produced due to rapid unload. Many researchers [21] have investigated this process from theoretical analysis, field monitoring, lab experiment, and numerical simulation. However, we should have a good understanding of this process. Modeling of zonal disintegration requires the nonlinear properties of the rock mass. We still puzzle on failure criterion. In this paper, we present a zonal disintegration simulation in one coal mine for comparison with the borehole teleview data. Such comparison points out the future research direction.

\section{Strain Softening Model}

In this study, the zonal disintegration in the form of broken zone in the surrounding rock is not completely discontinuous. The rock mass fracture but not separation is considered to study the zonal rupture problem, so FLAC, which is usually used as a numerical simulation software for numerical analysis of continuous media, was chosen.

2.1. Strain Softening Mohr-Coulomb Model. Figure 1(a) shows the relationship between stress and strain in this model. The strain is constituted by both elastic and plastic strains after yield trend. The variation of some parameters, such as cohesion, internal friction, and dilatancy angle, can be viewed as plastic shear strain related. Tensile strength is a function of plastic tensile strain.

2.2. Failure Criterion. The strain softening model in the software FLAC3D is based on Mohr-Coulomb with associated law of tensile flow and nonassociated law of shear flow. Therefore, the yield function, potential function, and plastic flow law of the Mohr-Coulomb are consistent with the general one.

$$
\begin{aligned}
& f^{s}=\sigma_{1}-\sigma_{3} N_{\varphi}+2 c \sqrt{N_{\varphi}}, \\
& f^{t}=\sigma_{t}-\sigma_{3},
\end{aligned}
$$

where $f^{\mathrm{s}}$ is shear yield function; $f^{\mathrm{t}}$ is tensile yield function; $\sigma_{1}$ is maximum principal stress; $\sigma_{3}$ is minimum principal stress; $\varphi$ is internal friction angle; $c$ is cohesion; $N_{\varphi}=(1+\sin \varphi) /(1-\sin \varphi) \sigma_{\mathrm{t}}$ is tensile strength. $g^{s}$ is the shear potential function corresponding to the nonassociated law of flow:

$$
g^{\mathrm{s}}=\sigma_{1}-\sigma_{3} N_{\varphi}
$$

$g^{t}$ is the tensile potential function corresponding to the associated law of flow:

$$
g^{t}=-\sigma_{3}
$$

For strength criterion of zonal disintegration, we use the maximum tensile stress in the Mohr-Coulomb model of the software FLAC3D.

2.3. FAI Index. Because FLAC3D is for continuum media mechanics, it is inconvenient to judge the failure state of rock mass. We introduce the YAI index to represent the degree of yield. The value of YAI is from 0 to 1 . In plastic mechanics, the Mohr-Coulomb yield function is

$$
\begin{aligned}
F(\sigma)= & \frac{1}{3} I_{1} \sin \varphi+\left(\cos \theta_{\sigma}-\frac{1}{\sqrt{3}} \sin \theta_{\sigma} \sin \varphi\right) \\
& \cdot \sqrt{J_{2}}-c \cos \varphi=0 .
\end{aligned}
$$

in which $I_{1}$ is the first invariant of stress tensor; $J_{2}$ is the second invariant of the deviatoric stress tensor; $\varphi$ is internal friction angle; $c$ is cohesion; $\theta_{\sigma}$ is Lode angle.

If we express formula (4) in terms of normal stress $\sigma_{\pi}$ and shear stress $\tau_{\pi}$, we have

$$
\begin{gathered}
F\left(\sigma_{\pi}, \tau_{\pi}, \theta_{\sigma}\right)=\frac{1}{\sqrt{3}} \sigma_{\pi} \sin \varphi+\frac{1}{\sqrt{2}}\left(\cos \theta_{\sigma}-\frac{1}{\sqrt{3}} \sin \theta_{\sigma} \sin \varphi\right) \\
\cdot \tau_{\pi}-c \cos \varphi=0 .
\end{gathered}
$$

in which $\sigma_{\pi}=I_{1} / \sqrt{3} ; \tau_{\pi}=\sqrt{2 J_{2}}$.

Suppose $\alpha=\sin \varphi / 3, \quad \beta=\left(\cos \theta_{\sigma}-\left(\sin \theta_{\sigma} \sin \varphi / \sqrt{3}\right)\right) /$ $\sqrt{2}, \gamma=-c \cos \varphi$, then

$$
F=\alpha \sigma_{\pi}+\beta \tau_{\pi}+\gamma=0 .
$$

The stress state of arbitrary one-point $Q$ on the $\pi$ plane is shown in Figure 1(c). The coordinate of point $Q$ is $\left(\sigma_{\pi}, \tau_{\pi}\right)$. The coordinate of point $C$ on the $\pi$ plane is $\left(\sigma_{\pi}, \tau_{\pi}^{\prime}\right)$. We define $\mathrm{YAI}=Q C / A_{0} C=1-\tau_{\pi} / \tau_{\pi}^{\prime}$ and apply formula (6) and denote $\tau_{\pi}^{\prime}$ as $\tau_{\pi}^{\prime}=\left(\alpha \sigma_{\pi}+\gamma\right) / \beta$. We obtain

$$
\mathrm{YAI}=\frac{\alpha \sigma_{\pi}+\beta \tau_{\pi}+\gamma}{\alpha \sigma_{\pi}+\gamma}
$$

Therefore, the expression of YAI in shear and tensile yield criterions is

$$
\mathrm{YAI}= \begin{cases}\frac{\alpha \sigma_{\pi}+\beta \tau_{\pi}+\gamma}{\alpha \sigma_{\pi}+\gamma}, & \frac{\sigma_{1}+\sigma_{3}}{2} \leq \sigma_{R}, \\ \frac{\sigma_{\mathrm{t}}-\sigma_{1}}{\sigma_{\mathrm{t}}-\sigma_{R}}, & \frac{\sigma_{1}+\sigma_{3}}{2}>\sigma_{R} .\end{cases}
$$

in which $\sigma_{\mathrm{t}}$ is tensile strength; $\sigma_{R}=\left(\sigma_{\mathrm{t}}-c \cos \varphi\right) /$ $(1-\sin \varphi)$. When $\left(\sigma_{1}+\sigma_{3}\right) / 2 \leq \sigma_{R}$, the YAI is shear yield criterion. When $\left(\sigma_{1}+\sigma_{3}\right) / 2>\sigma_{R}$, the YAI is tensile yield criterion. For rock material with main shear failure, the 


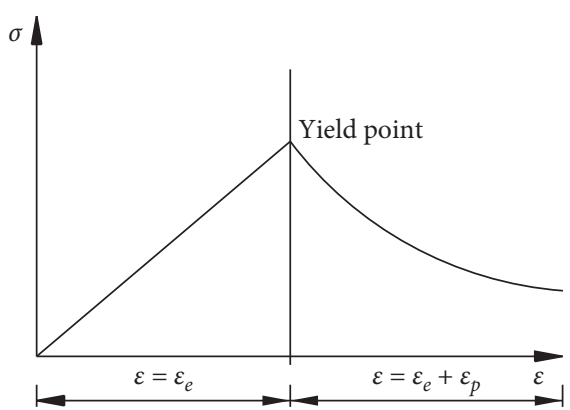

(a)

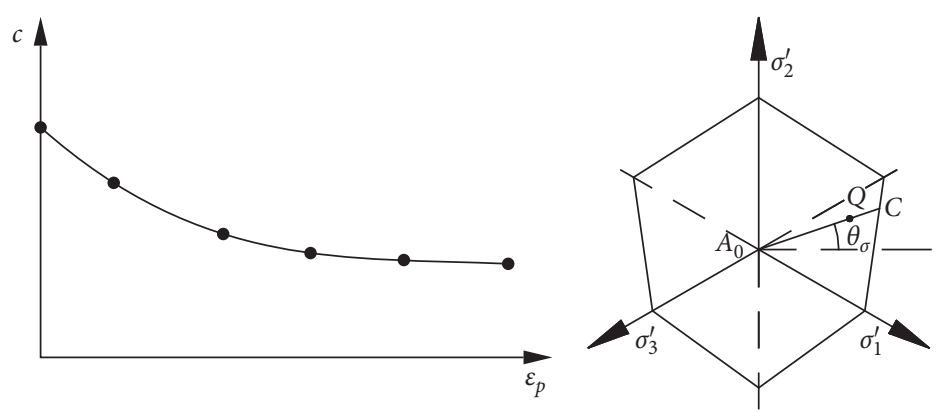

(b)

(c)

Figure 1: Strain softening Mohr-Coulomb model. (a) Stress-strain relationship. (b) Cohesion and plastic strain. (c) Relationship between stress point and yield plane on the $\pi$ plane.

plastic shear strain is usually used to describe strain softening. This is also called Failure Degree (FD).

$$
\mathrm{FD}=\frac{\gamma_{\mathrm{p}}}{\gamma_{\mathrm{p}}^{r}}
$$

in which $\gamma_{\mathrm{p}}^{r}$ is limit plastic shear strain, which is determined by the following formula:

$$
\gamma_{\mathrm{p}}=\sqrt{\frac{e_{i j}^{\mathrm{p}} e_{i j}^{\mathrm{p}}}{2}}
$$

where $e_{i j}^{\mathrm{p}}$ is plastic deviator strain and determined by the following formula:

$$
e_{i j}^{\mathrm{p}}=\varepsilon_{i j}^{\mathrm{p}}-\varepsilon_{m}^{\mathrm{p}} \delta_{i j}
$$

And $\gamma_{\mathrm{p}}$ is plastic shear strain of rock material $[22,23]$.

To analyze the numerical simulation results conveniently, we introduce the dangerous coefficient $w(w=1-$ YAI). Therefore, we can rewrite FAI as

$$
\mathrm{FAI}= \begin{cases}w, & 0 \leq w<1, \\ 1+\mathrm{FD}, & w=1, \mathrm{FD}>0\end{cases}
$$

From formula (12), the dangerous coefficient $w$ is used to evaluate dangerous degree before stress reaches yield state. The failure degree is represented as $1+\mathrm{FD}$ after rock mass reaches yield state. When FAI is between 0 and 1 , it represents that rock mass does not yield. When FAI equals 1.0, rock mass starts to yield into a plastic state. When FAI is more than 2.0, it represents that plastic shear strain has reached its limit. Rock mass is damaged at this state. From equations (8) and (12) we can simulate the whole process of failure using FAI in software FLAC3D. To display the location and scope of fracture zones, the elements with FAI bigger than 2.0 will be put into the "shear-break" group in the program and their stress state will be displayed on the nephogram.

\section{Realization of the Strain Softening Mohr-Coulomb Model}

3.1. Model Construction for Circular Deep Tunnel. To demonstrate our simulation approach, we use a case of zonal disintegration in a circular deep tunnel. The size of the model is $60 \mathrm{~m} \times 10 \mathrm{~m} \times 60 \mathrm{~m}$ and tunnel radius is $5.0 \mathrm{~m}$. Table 1 lists the physical-mechanical parameters of the rock $[21,24]$. The constraint condition at the model bottom is fixed. The model's initial displacement and velocity are zero. When the axial pressure of two times compressive strength (about $177 \mathrm{MPa}$ ) is exerted, the pressures on other planes are removed. The constraint conditions on other planes are modified simultaneously. We use the strain softening Mohr-Coulomb model as the constitutive model and the failure criterion of maximum tensile stress is used in this model. The sidewall is exerted with dynamic load to control the unload velocity to simulate the process of excavation. The calculation mode used is a dynamic one. The end calculation is controlled by the default displacement value.

3.2. Simulation Results. Figure 2 shows the simulation results. Many nephograms, such as cohesion, internal friction angle, YAI, FAI, maximum principal stress, minimum principal stress, plastic zone state, and fracture zone state, are shown.

Under high axial pressure, two fracture zones appear. From the cohesion and internal friction angle nephograms, the minimum value of cohesion and internal friction angle appear at certain distances from the tunnel. From the YAI nephogram, the YAI is between 0 and 0.2 at certain distances from the sidewall. We regard this as a fracture zone. The YAI increases gradually with the increase of the distance. With enough distance, the YAI decreases to the $0 \sim 0.2$ interval again. This indicates that another fracture zone is formed. From the FAI nephogram, the FAI is $0 \sim 2.0$ for distance interval of $4.64 \sim 5.03 \mathrm{~m}$. This indicates that one fracture zone is formed at a distance interval of $2.5 \sim 4.64 \mathrm{~m}$. Another fracture zone at a distance bigger than $5.03 \mathrm{~m}$ is also formed because FAI reaches more than 2.0 in this section. From the maximum and minimum principal stress nephograms, the maximum and minimum principal stresses increase gradually with the distance. The stress concentration emerges at the second fracture zone with the minimum principal stress demonstrating no change. It indicates that this location is very vulnerable to fracture. From the plastic and fracture zone nephograms, there is a nonfractured zone at the distance between 4.70 and $5.31 \mathrm{~m}$. The plastic shear strain reaches its limit when FAI is equal to or larger than 2.0. To 
TABLE 1: The mechanical parameters of the surrounding rock.

\begin{tabular}{lcccccc}
\hline $\begin{array}{l}\text { Weight } \\
\left(\mathrm{kN} / \mathrm{m}^{3}\right)\end{array}$ & $\begin{array}{c}\text { Elastic modulus } \\
(\mathrm{GPa})\end{array}$ & $\begin{array}{c}\text { Cohesion } \\
(\mathrm{MPa})\end{array}$ & $\begin{array}{c}\text { Internal friction angle } \\
\left({ }^{\circ}\right)\end{array}$ & $\begin{array}{c}\text { Tensile strength } \\
(\mathrm{MPa})\end{array}$ & $\begin{array}{c}\text { Compressive strength } \\
(\mathrm{MPa})\end{array}$ & $\begin{array}{c}\text { Poisson's } \\
\text { ratio }\end{array}$ \\
\hline 26.2 & 12.97 & 10 & 40 & 14.01 & 88.55 \\
\hline
\end{tabular}

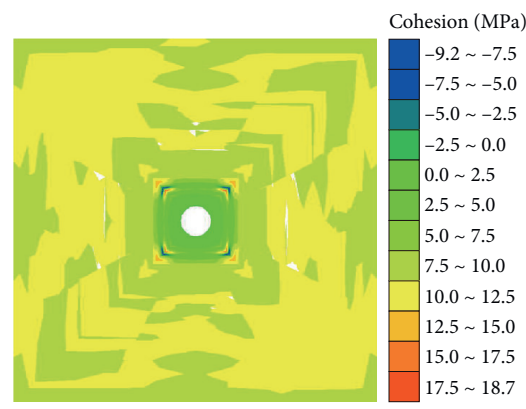

(a)

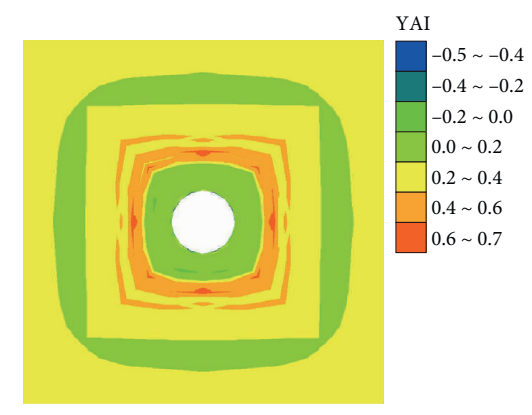

(c)

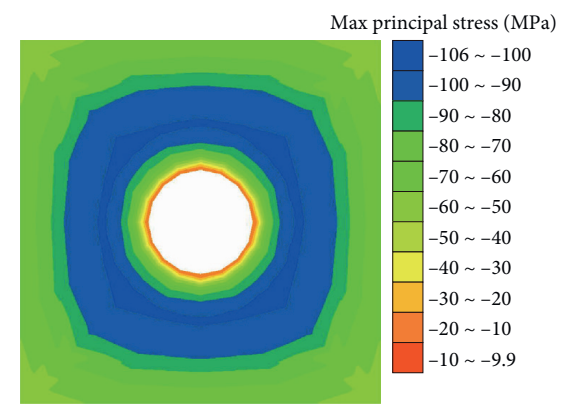

(e)

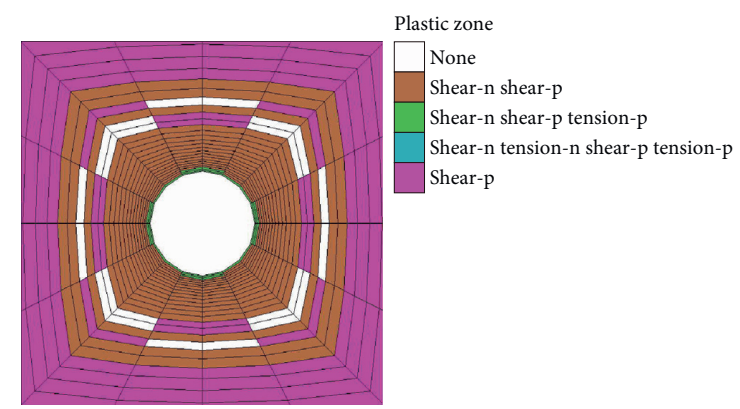

(g)

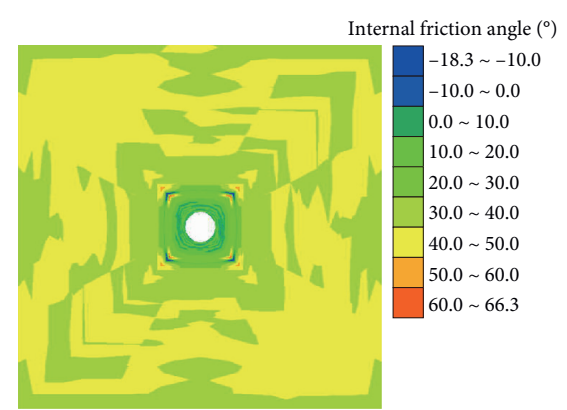

(b)

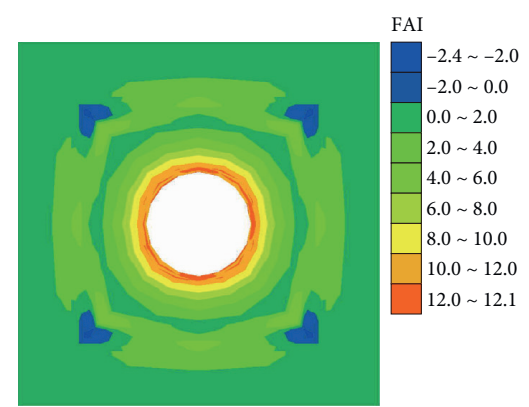

(d)

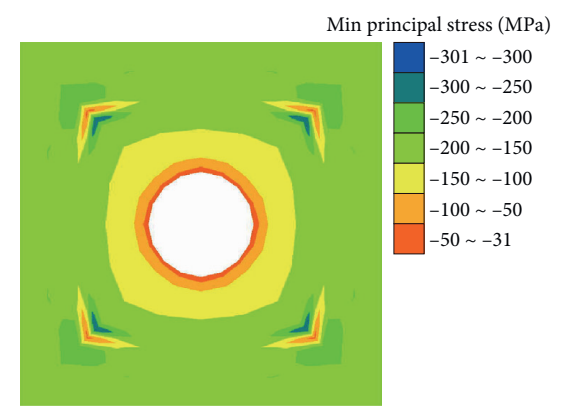

(f)

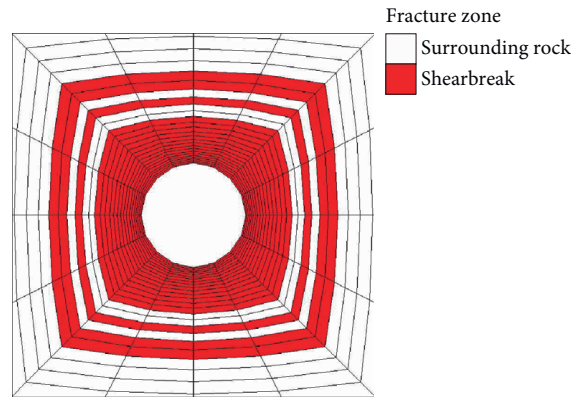

(h)

FIgURe 2: Simulation results. (a) Cohesion. (b) Internal friction angle. (c) YAI. (d) FAI. (e) Max principal stress. (f) Min principal stress. (g) Plastic zone. (h) Fracture zone.

show the nonfractured zone and fractured zone clearly, the element with FAI equal or larger than 2.0 is marked as "shearbreak" group in Figure $2(\mathrm{~h})$. The second small fractured zone emerges in a nonfractured zone. The nonfractured and fractured zone distributions are $2.5 \mathrm{~m} \sim 4.73 \mathrm{~m}$, $4.73 \mathrm{~m} \sim 5.33 \mathrm{~m}$, and $5.33 \mathrm{~m} \sim 6.93 \mathrm{~m}$, respectively. The widths 
of fractured zones are $2.23 \mathrm{~m}$ and $1.60 \mathrm{~m}$, while the width of a nonfractured zone is only $0.60 \mathrm{~m}$.

\subsection{Zonal Disintegration Mechanism}

3.3.1. Generation Process of Zonal Disintegration. The failure of a deep tunnel appears at the sidewall in the initial stage of excavation due to stress concentration. The distribution of radial and tangential stresses is shown in Figure 3(a). The radial stress increases from zero to initial stress and tangential stress decreases from concentration stress to initial stress. This stress distribution is shown in Figure 3(b), in which $R$ is the distance to the tunnel center and $C$ is the distance from elastic/plastic interface to the tunnel center. When $R$ is less than $C$, both radial and tangential stresses increase with $R$. When $R$ is equal to $C$, the tangential stress reaches its maximum and it will decrease with the increase of $R$ until it returns to the initial stress. The radial stress increases with $R$ until it returns to the initial stress. This indicates that, at the location of elastic and plastic interface, a special zone exists to support the pressure of surrounding rock. We call this zone Pressure Support Zone (PSZ). There are two stress states in PSZ. One is $\sigma_{\theta}>\sigma_{z}>\sigma_{r}$, where the tangential stress is the maximum principal stress, radial stress is the minimum principal stress, and the axial stress is the intermediate. The other is $\sigma_{z}>\sigma_{\theta}>\sigma_{r}$, where the axial stress is the maximum principal stress, the tangential stress is the intermediate principal stress, and the radial stress is the minimum principal stress. In SPZ, when the tensile stress reaches the tensile strength, failure and fracture will appear. The failure will form an annular tensile fissure because the circular tunnel stress distribution has axial symmetry. In essence, the failure makes a new tunnel of a bigger radius. The redistributed stress is shown in Figure 3(c). New fractured zones emerge under high tangential and axial stress and stress undergoes another redistribution as shown in Figure 3(d). This process pushes the PSZ zone outwards until the stress in the zone does not create tensile failures. The generation process of zonal disintegration is shown in Figure 3.

From Figure 2(f), we can see that the minimum principal stress increases with $R$. It peaks between the first nonfractured zone and the second fractured zone. The maximum principal stress peaks at the interface of the first fractured zone and nonfractured zone as shown in Figure 2(e).

3.3.2. Influence Factors of Zonal Disintegration. There are many factors that influence zonal disintegration. In what follows, we will describe all major factors such as mechanical properties of the surrounding rock, unloading velocity, stress, and tunnel size and shape.

(1) Process of Unloading. Tunnel excavation is a process of unloading. To simulate this process, we use dynamic and static load of inverse direction applied to the tunnel sidewall. The control of unloading velocity is through exerting static load of inverse direction, which is shown in Figure 4.
From our modeling, the width of fractured zone created by fast unloading is bigger than that of slow unloading. Both fast and slow unloading can generate zonal disintegration.

(2) Direction of Maximum Principal Stress. We consider two cases where the direction of maximum principal stress is either parallel or perpendicular to the tunnel axis. Figure 5 shows the fractured and plastic zone for maximum principal stress perpendicular to tunnel axis. In comparison of Figures $5,2(\mathrm{~g})$, and $2(\mathrm{~h})$, we found that the plastic zone scope at the top and bottom of the tunnel is less than that at the tunnel side. There is no zonal disintegration when the maximum principal stress is vertical to the tunnel axis. This proves that high horizontal stress is necessary for zonal disintegration generation. The main reason is that high axial stress causes the deformation towards the free face during excavation. The radial displacement of the sidewall causes big radial tensile strain. The tensile failure happens when the radial tensile strain reaches its limit.

(3) Axial Stress. To understand the influence of axial stress on zonal disintegration, we simulated three cases where the axial stress is two times, one time, and 0.8 times that of the compressive strength. Figure 6 shows the plastic and fractured zone for the last two axial stresses.

In comparison of Figures 6, 2(g), and 2(h), we can see that the width of fractured zone with axial stress of 1 time the uniaxial compressive strength is less than that of 2 times. For the axial stress of 0.8 times the uniaxial compressive strength, no zonal disintegration is generated. The width of fractured zone increases with that of the axial stress. The plastic circle around the tunnel with zonal disintegration is smaller than that without zonal disintegration. It demonstrates that zonal disintegration reduces the rock stability capacity. Zonal disintegration happens when axial stress is larger than the uniaxial compressive strength.

(4) Radius of Tunnel. In Section 3, we simulated the $2.5 \mathrm{~m}$ radius. In this section, the radii of 5.0 and $1.0 \mathrm{~m}$ are considered. Figure 7 shows the plastic and fractured zones for these two radiuses.

The nonfractured and fractured zones for $5 \mathrm{~m}$ radius are $5.0 \mathrm{~m} \sim 6.8 \mathrm{~m}, 6.8 \sim 7.1 \mathrm{~m}$, and $7.1 \mathrm{~m} \sim 11.8 \mathrm{~m}$, respectively. The widths of fractured zones are $1.8 \mathrm{~m}$ and $4.7 \mathrm{~m}$, respectively, and the width of nonfractured zone is $0.3 \mathrm{~m}$. The nonfractured and fractured zones for $1 \mathrm{~m}$ radius are $1.0 \mathrm{~m} \sim 1.9 \mathrm{~m}, 1.9 \sim 2.7 \mathrm{~m}$, and $2.7 \mathrm{~m} \sim 3.5 \mathrm{~m}$, respectively. The widths of fractured zones are $0.9 \mathrm{~m}$ and $0.8 \mathrm{~m}$, respectively, and the width of nonfractured zone is $0.8 \mathrm{~m}$. The width of fractured zone increases gradually with the tunnel radius and the width of nonfractured zone decreases gradually.

(5) Tunnel Shape. We compare the arch rectangular tunnel to circular tunnel in this section. The arch radius is $2.5 \mathrm{~m}$ and the height of sidewall is $1.38 \mathrm{~m}$. We keep the boundary conditions and parameters unchanged from the previous models. Figure 8 shows the plastic and fractured zones.

In comparison with the circular tunnel, though the scope of fractured zone becomes bigger, there is no zonal 


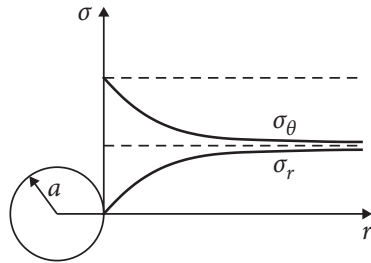

(a)

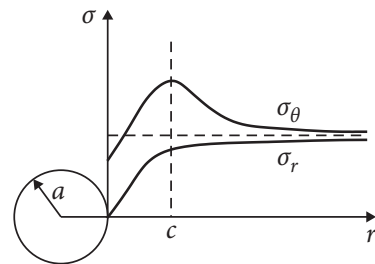

(b)

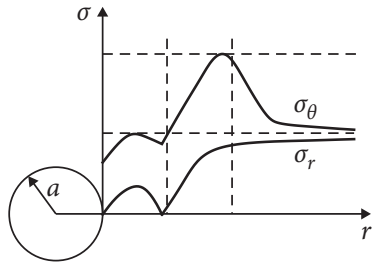

(c)

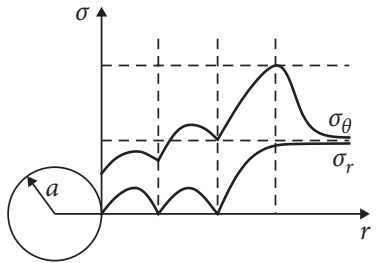

(d)

Figure 3: Generation process of zonal disintegration in a deep tunnel. (a) Elastic. (b) Elastic and plastic. (c) One fractured zone. (d) Two fractured zones.

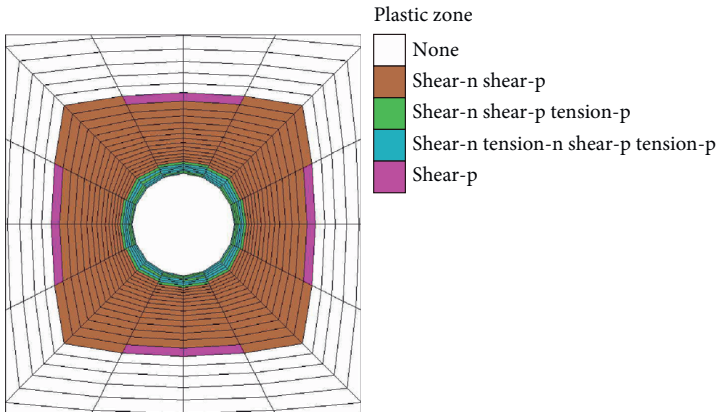

(a)

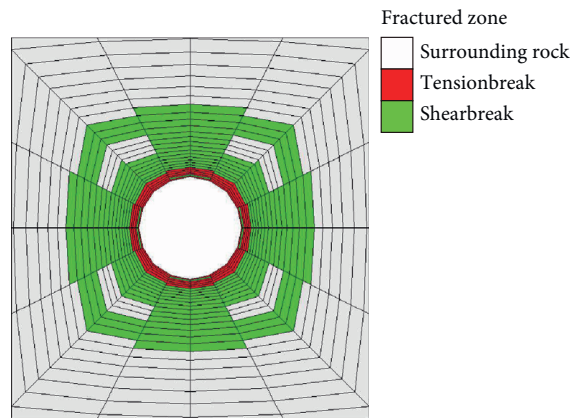

(b)

Figure 4: Static process. (a) Plastic zone. (b) Fractured zone.

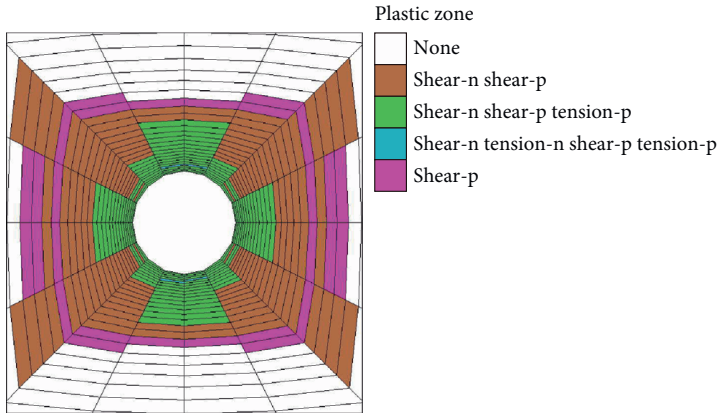

(a)

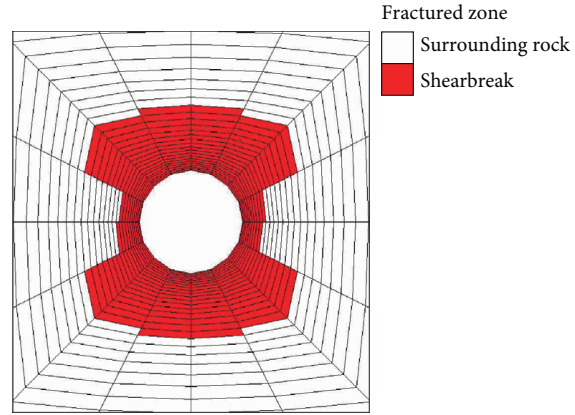

(b)

FIgURE 5: Direction of maximum principal stress. (a) Plastic zone. (b) Fractured zone.

disintegration in the sidewall. The zonal disintegration at the arch is similar to that of the circular tunnel. The zonal disintegration at the tunnel bottom is less obvious than that at the arch. The scope of plastic zone at the sidewall is big. The shape of zonal disintegration is similar to that of the tunnel. We further conclude that the shape of zonal disintegration is similar to the shape of the tunnel.

\section{Case Studies}

4.1. General Settings. A deep tunnel from Huainan-Dingji mine in China is simulated to verify the zonal disintegration prediction. The tunnel is about $955 \mathrm{~m}$ deep with elevation of $-910 \mathrm{~m}$. The tunnel is arch rectangular with dimension of $5.00 \mathrm{~m} \times 3.88 \mathrm{~m}$. Permian upper Series Shihezi formation surrounds the tunnel and the predominant lithology is sandy mudstone, medium sandstone, silt-fine sandstone, and fine sandstone. Figure 9 shows the rock mass types. We used the medium sandstone's physical and mechanical parameters for simulation [21, 24] Physical and mechanical parameters for simulation are shown in Table 2.

Four sections in a roadway are thoroughly investigated by Chen et al. [5] for zonal disintegration. Three to four bores are arranged in each section. The bore fracturing is observed by a TV imager and zonal disintegration distributions in four sections are obtained. The geostatic stress is about $25 \mathrm{MPa}$ and lateral pressure coefficient is 1.5 . The model is shown in Figures 10 and 11.

4.2. Model Construction. The mesh is $60 \mathrm{~m} \times 10 \mathrm{~m} \times 60 \mathrm{~m}$ $(X \times Y \times Z)$ and the geostatic stresses with different directions are applied on different faces of the model. The size of 


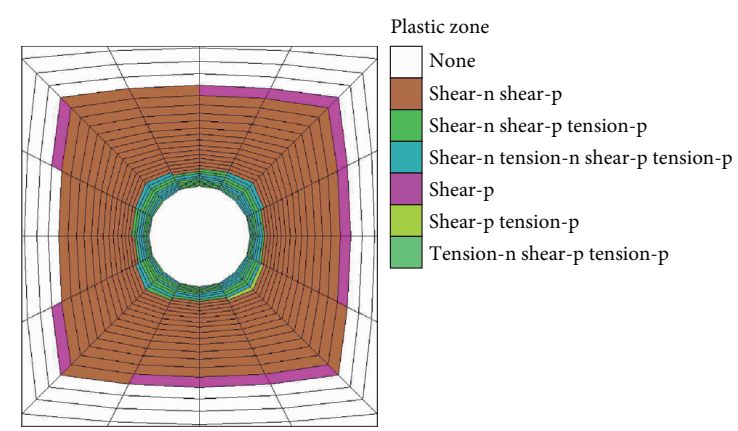

(a)

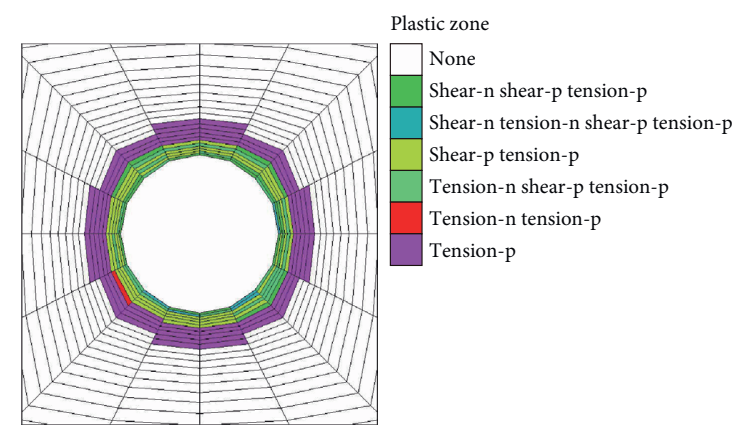

(c)

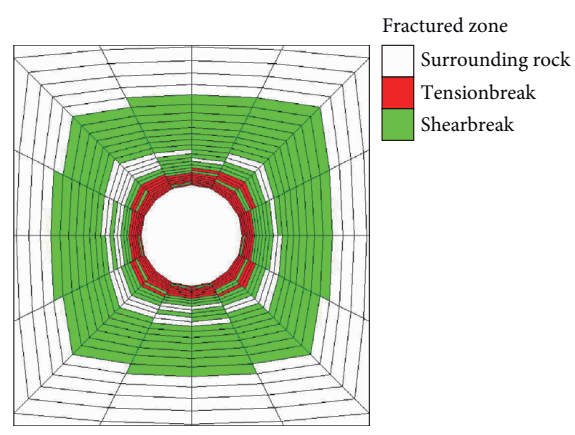

(b)

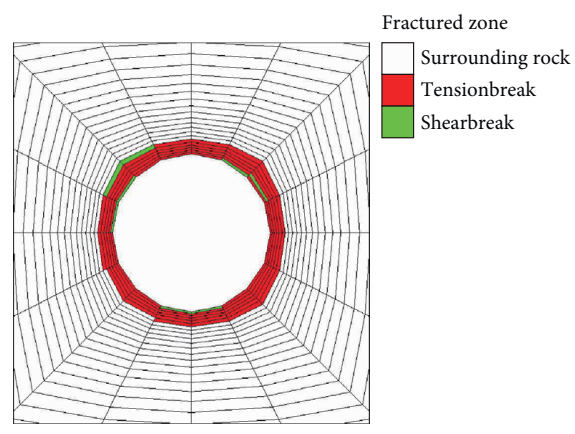

(d)

Figure 6: The plastic and fractured zones under different axial stress. (a) Plastic zone (1 time). (b) Fractured zone (1 time). (c) Plastic zone (0.8 time). (d) Fractured zone (0.8 time).

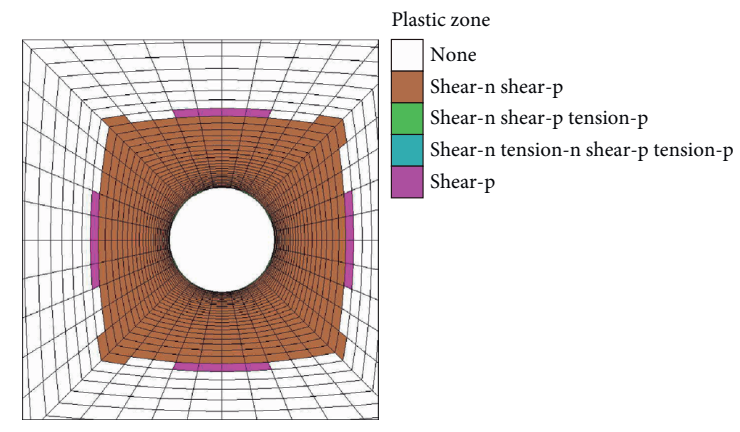

(a)

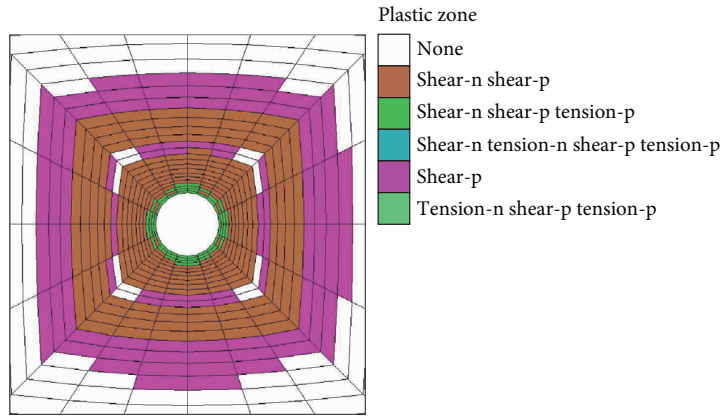

(c)

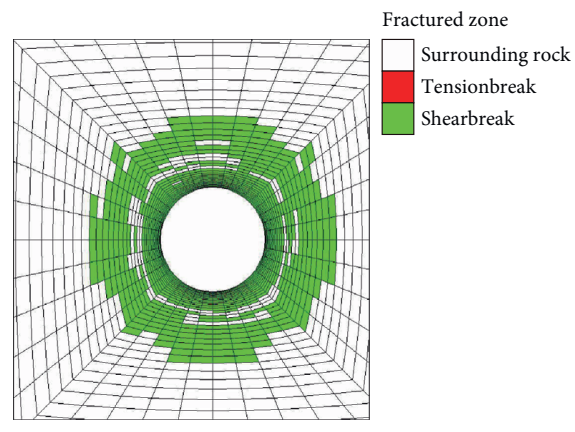

(b)

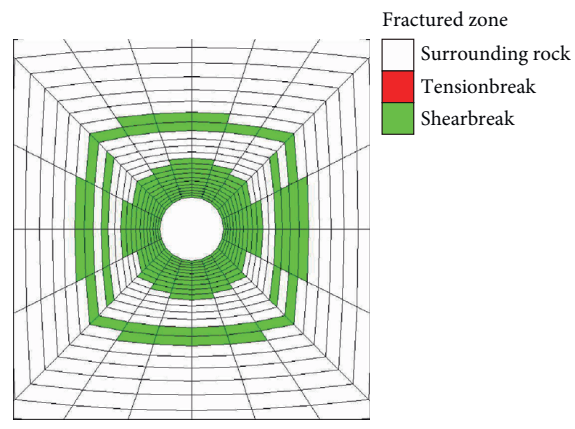

(d)

FiguRe 7: Plastic and fractured zones for two radiuses. (a) Plastic zone $(r=5.0 \mathrm{~m})$. (b) Fractured zone $(r=5.0 \mathrm{~m})$. (c) Plastic zone $(r=1.0 \mathrm{~m})$. (d) Fractured zone $(r=1.0 \mathrm{~m})$. 


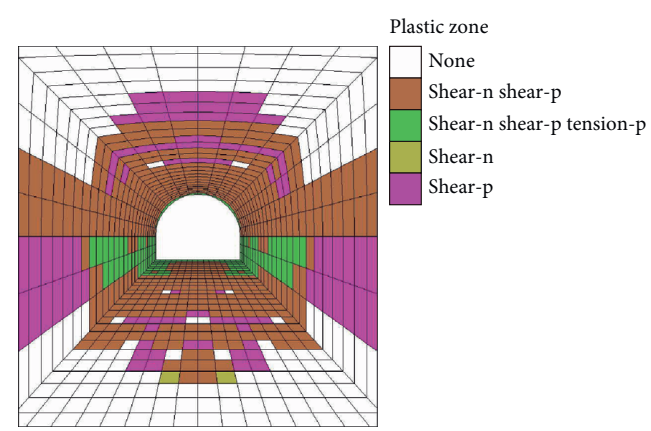

(a)

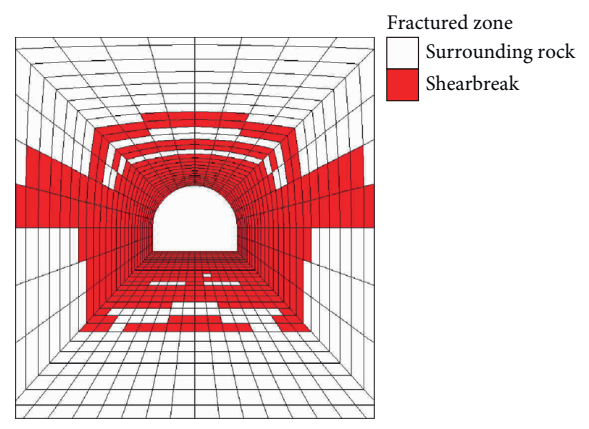

(b)

Figure 8: The plastic and fractured zones for arch rectangular tunnel. (a) Plastic zone. (b) Fractured zone.

\begin{tabular}{|c|c|c|c|}
\hline Stratum & Legend & $\begin{array}{l}\text { Thickness } \\
\text { (m) }\end{array}$ & Lithology \\
\hline \multirow{4}{*}{$\begin{array}{l}\text { Permian } \\
\text { system } \\
\text { Upper } \\
\text { shihezi } \\
\text { group }\end{array}$} & 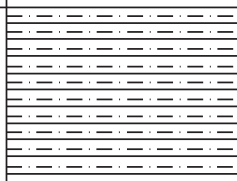 & 8.90 & $\begin{array}{c}\text { Sandy } \\
\text { mudstone }\end{array}$ \\
\hline & 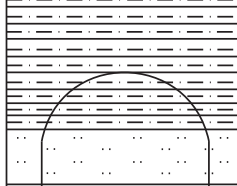 & 1.60 & $\begin{array}{l}\text { Medium } \\
\text { mudstone }\end{array}$ \\
\hline & 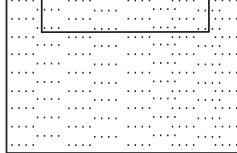 & 4.70 & $\begin{array}{l}\text { Silt-fine } \\
\text { mudstone }\end{array}$ \\
\hline & 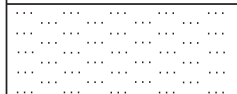 & 2.80 & $\begin{array}{c}\text { Fine } \\
\text { mudstone }\end{array}$ \\
\hline
\end{tabular}

FIGURE 9: Surrounding rock near tunnel.

TABLE 2: Physical and mechanical parameters for simulation.

\begin{tabular}{|c|c|c|c|c|c|c|c|}
\hline Lithology & $\begin{array}{l}\text { Weight } \\
\left(\mathrm{kN} / \mathrm{m}^{3}\right)\end{array}$ & $\begin{array}{l}\text { Elastic modulus } \\
\qquad(\mathrm{GPa})\end{array}$ & $\begin{array}{l}\text { Cohesion } \\
(\mathrm{MPa})\end{array}$ & $\begin{array}{c}\text { Internal friction } \\
\text { angle }\left({ }^{\circ}\right)\end{array}$ & $\begin{array}{l}\text { Tensile strength } \\
(\mathrm{MPa})\end{array}$ & $\begin{array}{l}\text { Compressive strength } \\
(\mathrm{MPa})\end{array}$ & $\begin{array}{l}\text { Poisson } \\
\text { ratio }\end{array}$ \\
\hline $\begin{array}{l}\text { Medium } \\
\text { sandstone }\end{array}$ & 26.2 & 12.97 & $10 \sim 15$ & $40 \sim 43$ & 14.01 & 88.55 & 0.268 \\
\hline
\end{tabular}

the excavation section is $5.00 \mathrm{~m} \times 3.88 \mathrm{~m}$, which is horseshoe shaped. In the initial geostress calculation, the normal constraint is applied only at the bottom $(Z=-30 \mathrm{~m})$ to limit the displacement in the $Z$ direction. A force $\sigma_{z}(25 \mathrm{MPa})$ is applied to the upper surface $(Z=30 \mathrm{~m})$, which is used to simulate the effect of the upper load. The horizontal stress $\sigma_{x}$, whose value is $37.5 \mathrm{MPa}$, is applied in the direction perpendicular to the axial direction of the cavern ( $X$ direction). Axial stress $\sigma_{y}$, whose value is $177.1 \mathrm{MPa}$, is applied in the axial direction of the chamber ( $Y$ direction). Before excavation simulation, the surface pressure is removed and the axial pressure of $177.1 \mathrm{MPa}$ is applied. The cohesion and internal friction angle are changeable with the plastic shear strain. The change law is shown in Figure 12. The calculation mode employed is a dynamic calculation one.
The unload velocity is controlled by applying an inverse dynamic load on the tunnel sidewall. The period of unload is $2.5 \mathrm{~ms}$ and peak strength is $38.4 \mathrm{MPa}$. The relationship between unload strength and time is

$$
\sigma(t)= \begin{cases}\sigma_{\max } \cos (w t), & t_{0} \geq t \geq 0 \\ 0, & t>t_{0}\end{cases}
$$

\subsection{Results}

4.3.1. Zonal Disintegration. Figure 13 shows the failure development and principal stress. Shear failure first appears at the top section, and then junction between sidewall and bottom. As the fractured zone extends outside, the zonal 


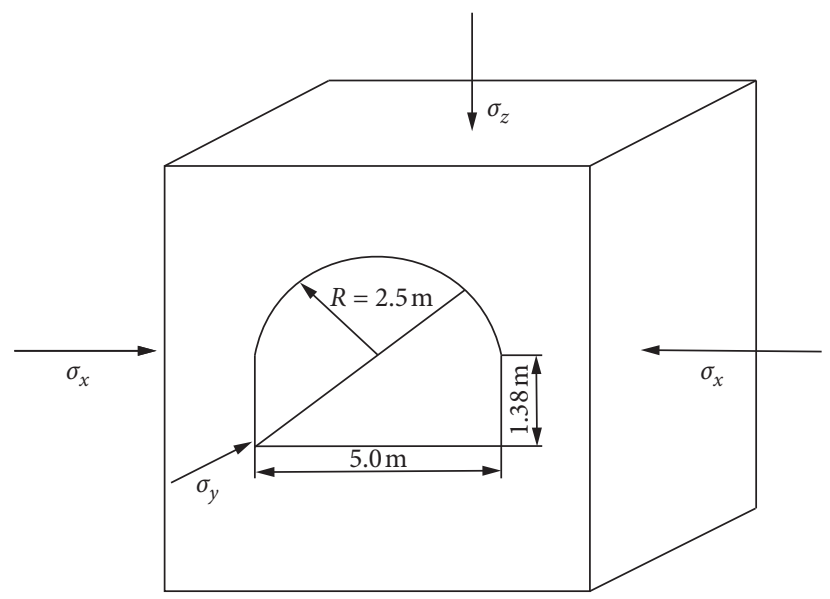

FIgURE 10: Model of tunnel.

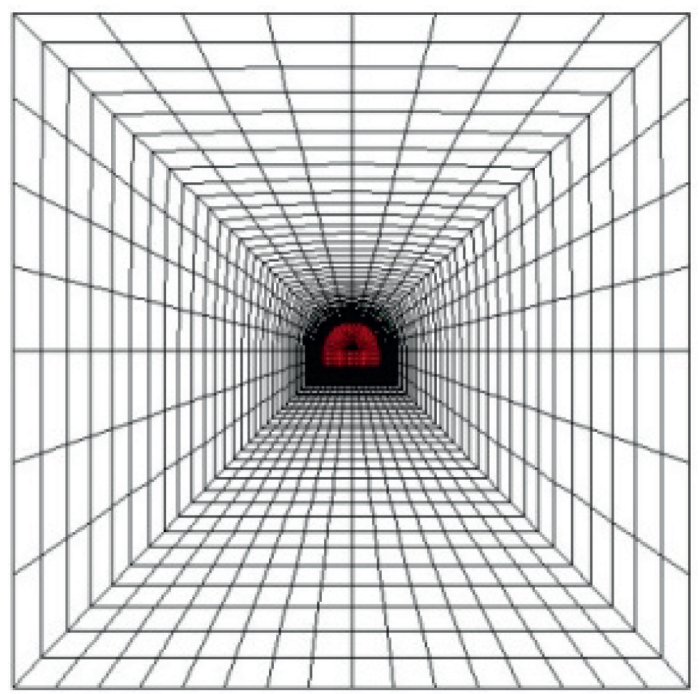

Figure 11: Tunnel section and mesh. grid.

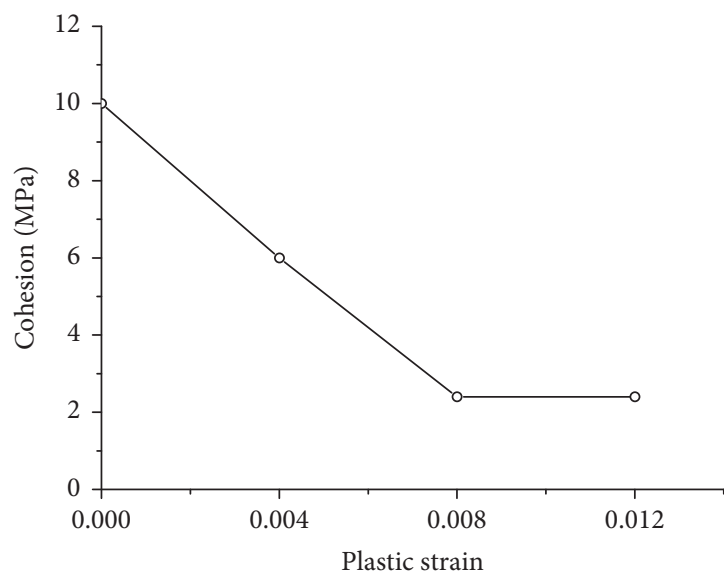

(a)

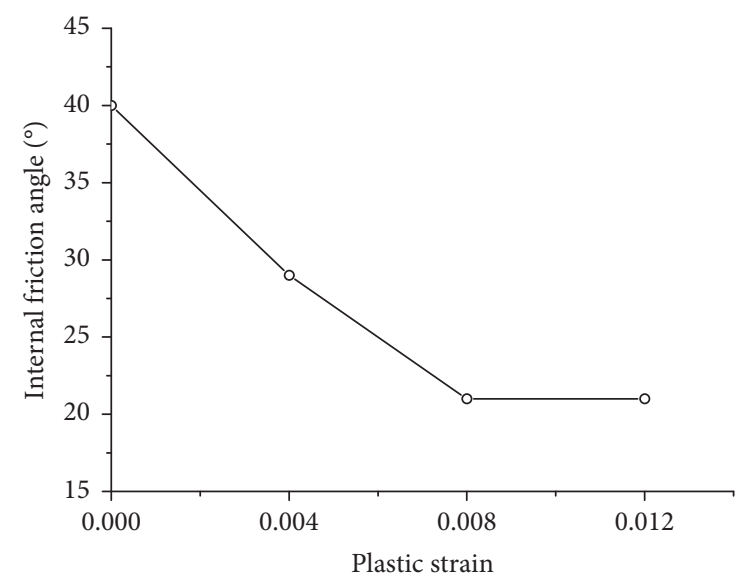

(b)

FIgURE 12: Relationship between strength parameters and plastic strain. (a) Cohesion. (b) Internal friction angle. 


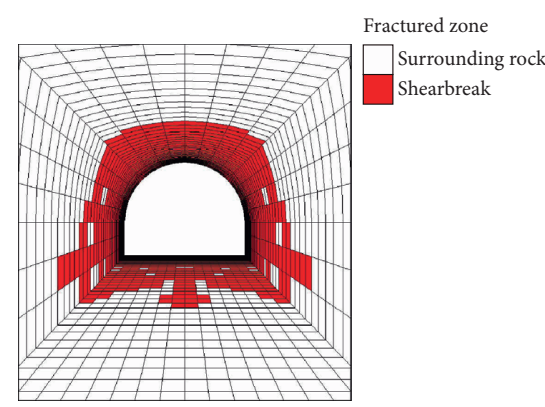

(a)

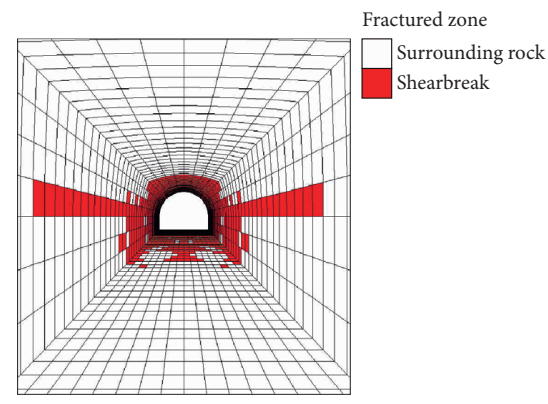

(d)

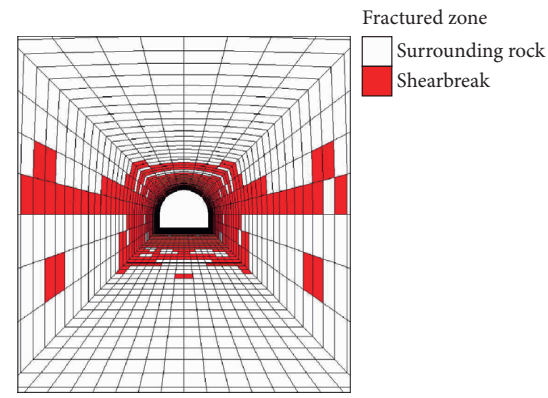

(g)

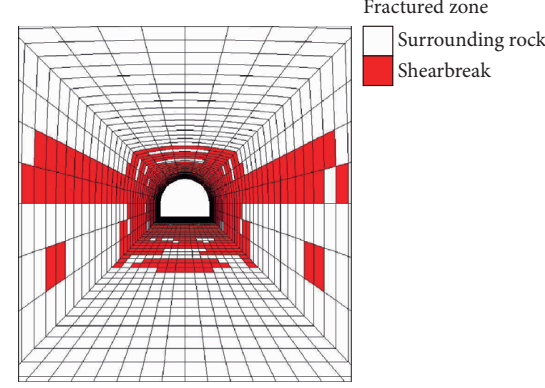

(j)

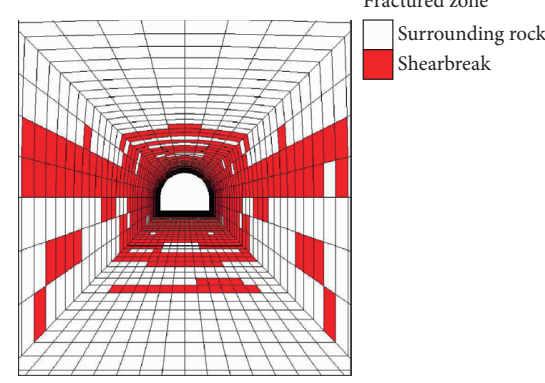

(m)

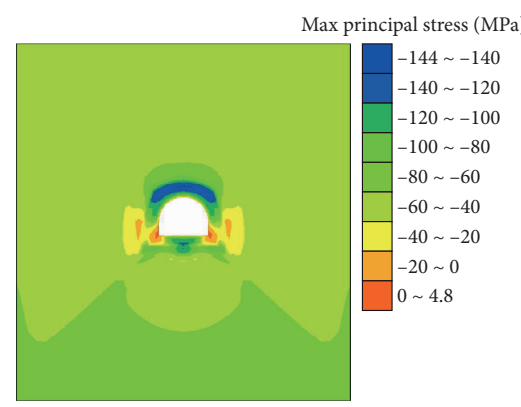

(b)

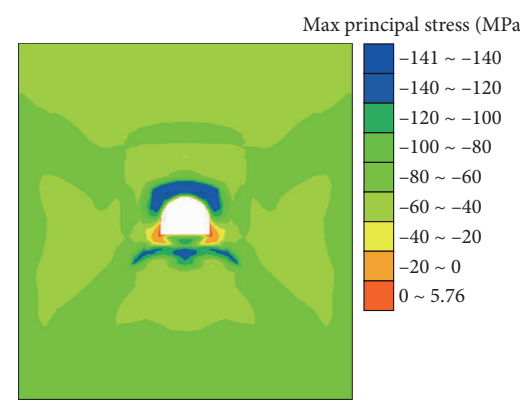

(e)

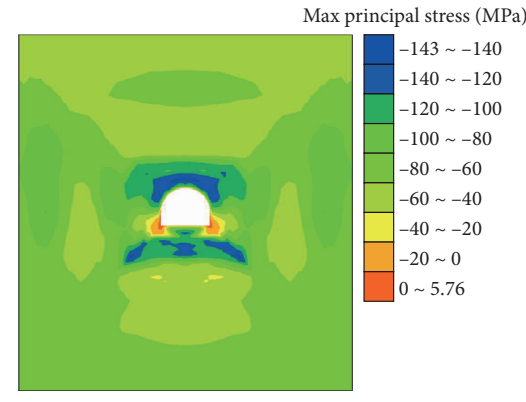

(h)

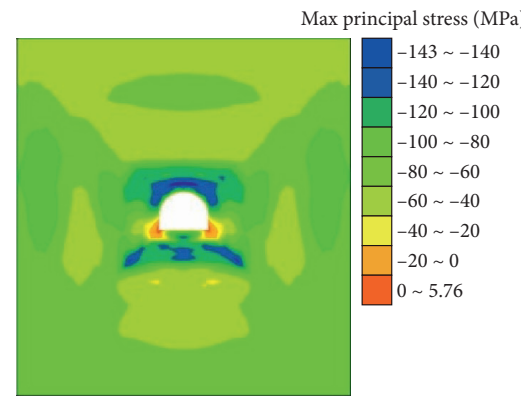

(k)

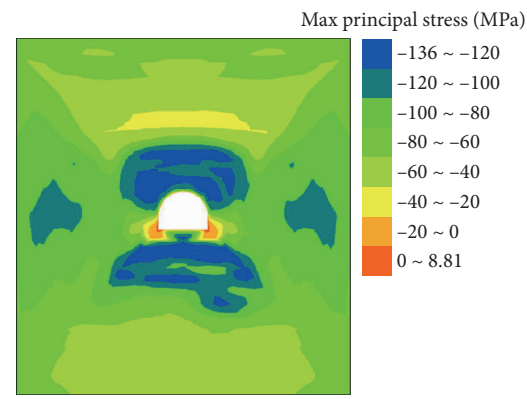

(n)

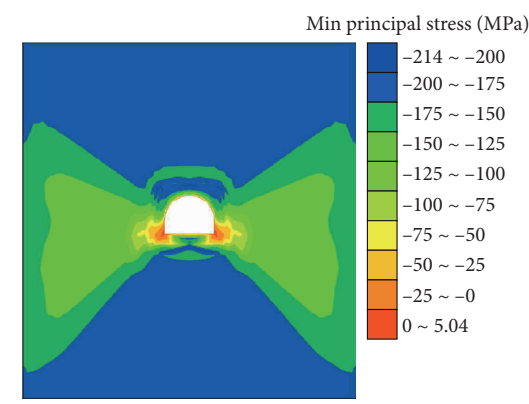

(c)

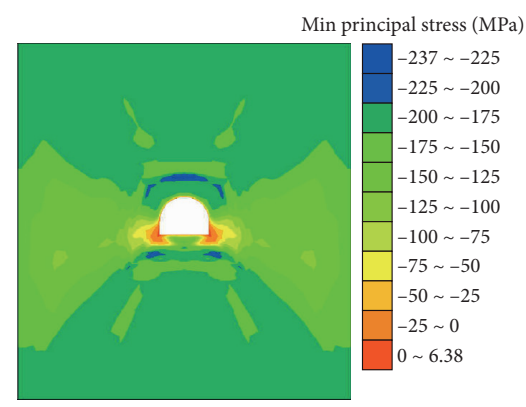

(f)

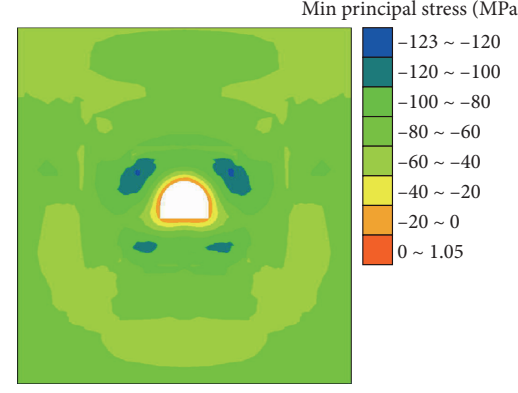

(i)

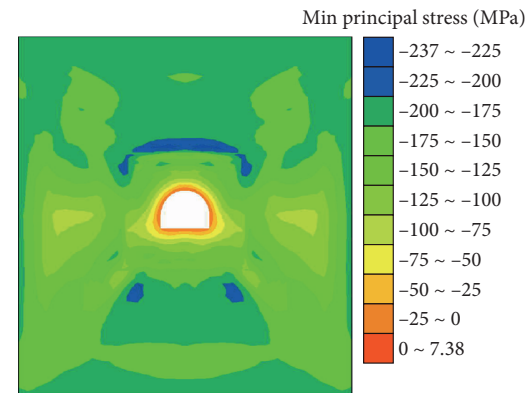

(1)

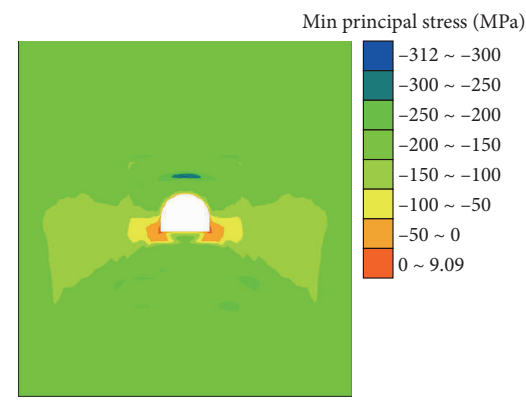

(o)

Figure 13: Continued. 


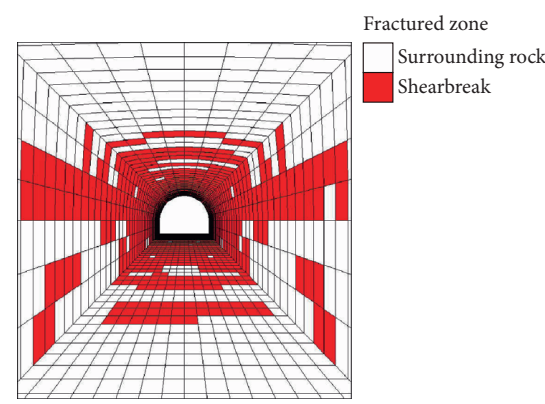

(p)

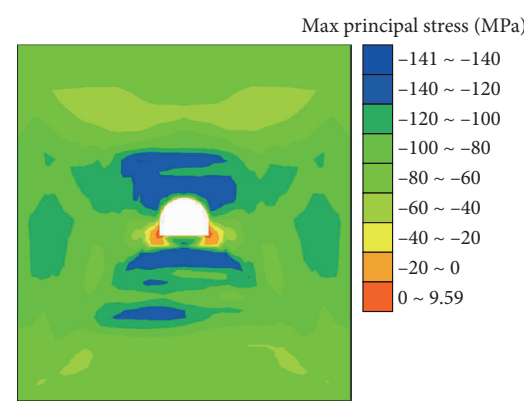

(q)

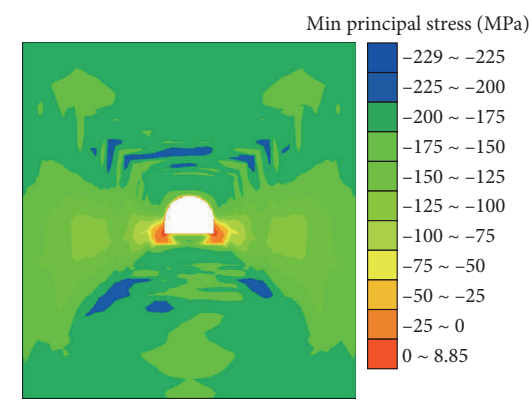

$(\mathrm{r})$

Figure 13: Failure and principal stress at different calculation steps. (a) Fractured zone (25000 steps). (b) Maximum principal stress (25000 steps). (c) Minimum principal stress (25000 steps). (d) Fractured zone (35000 steps). (e) Maximum principal stress (35000 steps). (f) Minimum principal stress (35000 steps). (g) Fractured zone (45000 steps). (h) Maximum principal stress (45000 steps). (i) Minimum principal stress (45000 steps). (j) Fractured zone (55000 steps). (k) Maximum principal stress (55000 steps). (m) Minimum principal stress (55000 steps). (n) Fractured zone (66000 steps). (o) Maximum principal stress (66000 steps). (p) Minimum principal stress (66000 steps). (q) Fractured zone (75000 steps). (r) Maximum principal stress (75000 steps). (s) Minimum principal stress (75000 steps).

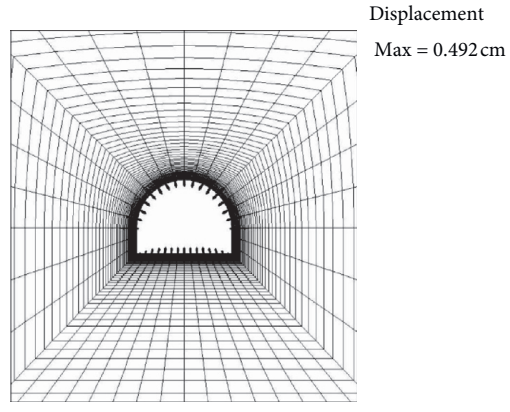

(a)

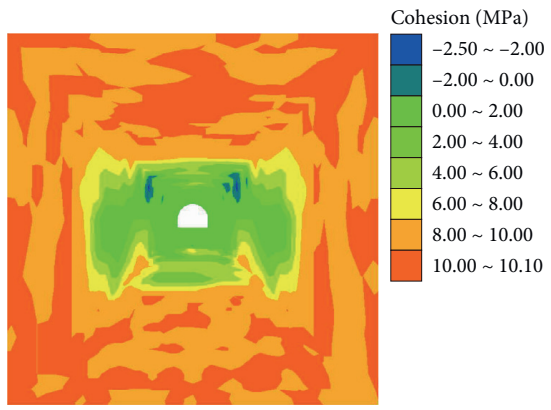

(c)

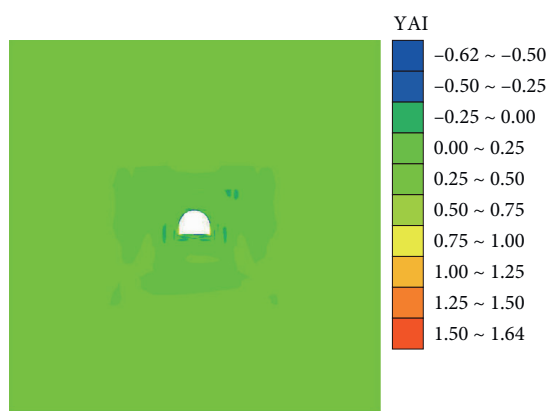

(e)

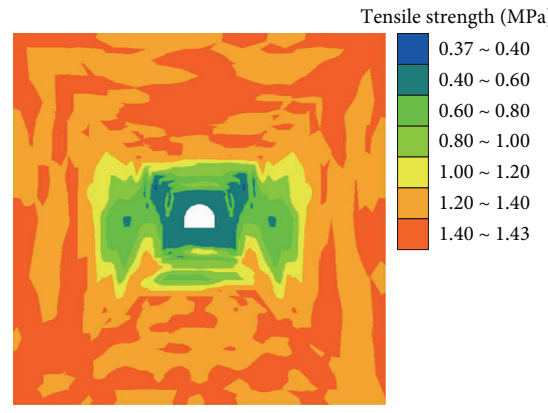

(b)

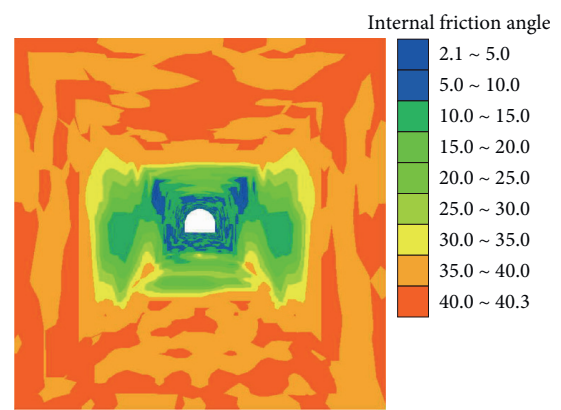

(d)

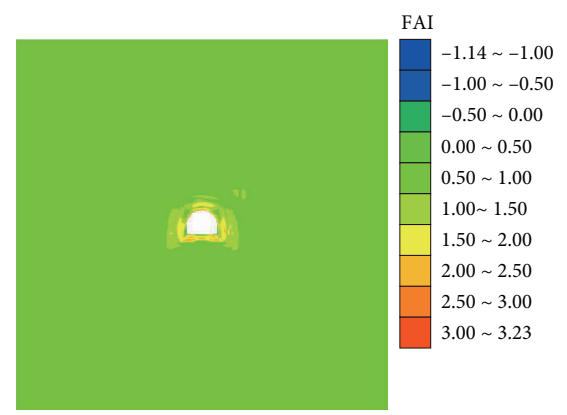

(f)

Figure 14: Continued. 


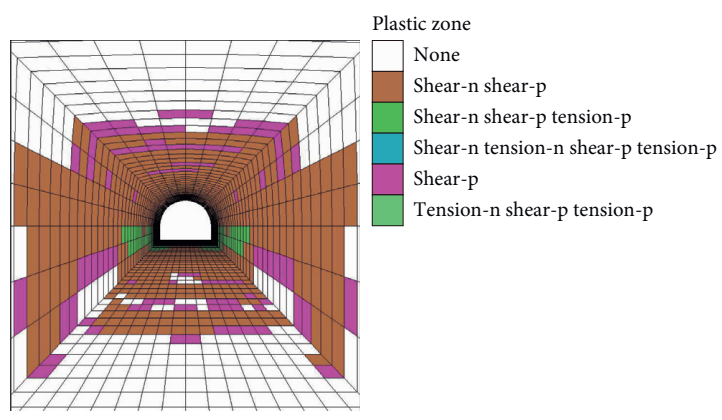

(g)

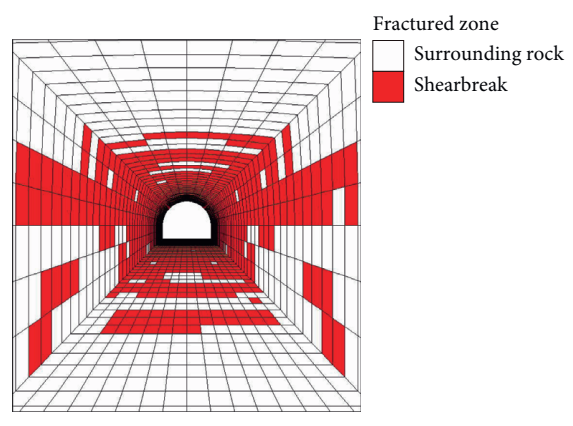

(h)

FIGURE 14: Final state of the surrounding rock. (a) Displacement. (b) Tensile strength. (c) Cohesion. (d) Internal friction angle. (e) YAI. (f) FAI. (g) Plastic zone. (h) Fractured zone.

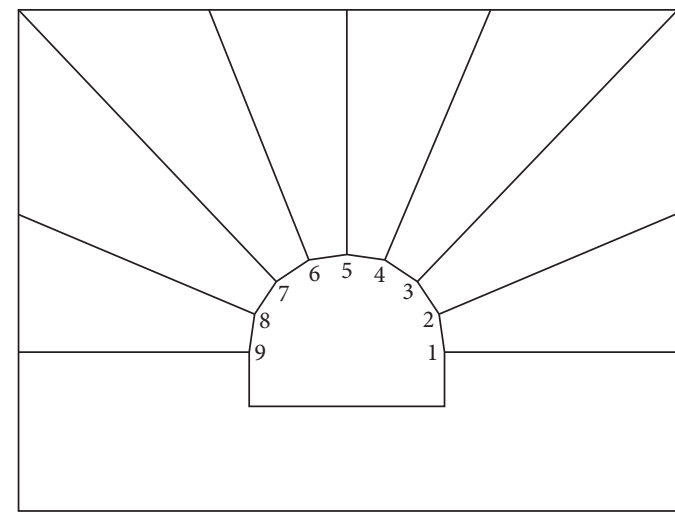

(a)

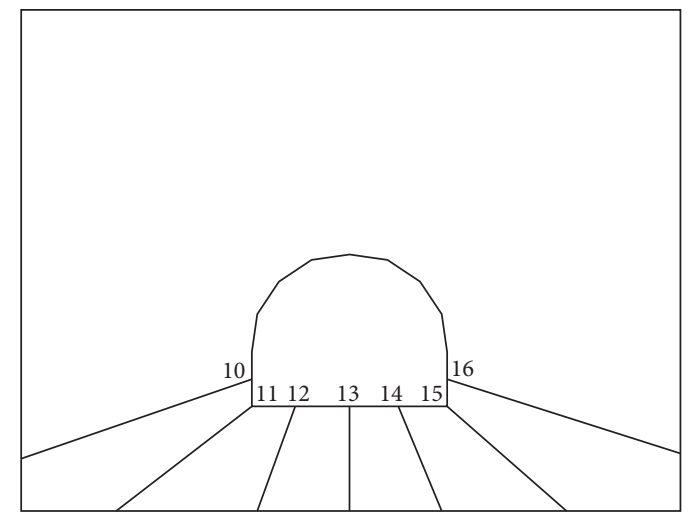

(b)

Figure 15: Arrangement of survey lines.

disintegration emerges at the sidewall and bottom section. Zonal disintegration is more remarkable at the sidewall and there are two fractured zones. The fractured zones propagate slowly towards the top and the bottom of the tunnel. Based on the nephogram of principal stress, the sidewall can be viewed as plastic loose circle. The properties of surrounding rock change from brittle to ductile gradually under the condition of high ground stress. The compressive strength of surrounding rock becomes higher due to large confining pressures. From Figures $13(\mathrm{~g})-13(\mathrm{~m})$, the top and bottom of tunnel show obvious zonal disintegration at calculation step of 45000 . Three fractured zones emerge at the top and two fractured zones emerge at the bottom. The scope of fractured zone at the sidewall increases with calculation steps. The width of fractured zone no longer extends outside.

There are three fractured zones on the top and two failure zones at the sidewall when the calculation reaches 65000 steps. The zonal disintegration at the bottom is remarkable. When calculation reaches 75000 steps, the fourth fractured zone at the top and the third fractured zone at the bottom are formed.

4.3.2. Final State of the Surrounding Rock. Figure 14 shows the final state of the surrounding rock after tunnel excavation. It includes displacement vector, tensile strength, cohesion, internal friction angle, YAI, FAI, and plastic and fractured zones. The displacement of sidewall and junction between sidewall and bottom is small. The displacements at the middle section of top and bottom are big. The unload scope due to excavation can be seen from the nephogram. We mark the elements with FAI larger than 2.0 in red color. The number of fractured zones can be easily found from Figure 14(h).

\subsection{Fractured Zones in the Surrounding Rock}

4.4.1. Arrangement of Survey Lines. Sixteen survey lines are arranged to test the fracture zone simulation as shown in Figure 15. Nine lines are at the top and seven lines are at the sidewall and bottom.

The FAI for every survey line is monitored during numerical simulation. There are 75 elements traversed by each survey line. When the FAI of an element is more than 2.0, this element fails because its shear strain has reached the limit. Figure 16 shows FAI at each survey line.

Table 3 shows the distribution scope of nonfractured zones for different survey lines. Inner Diameter (ID) 


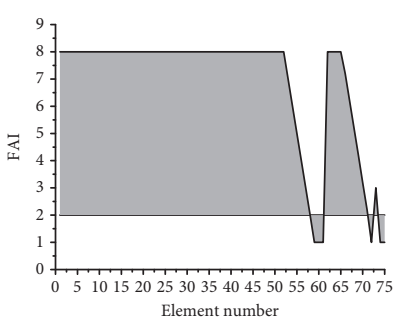

(a)

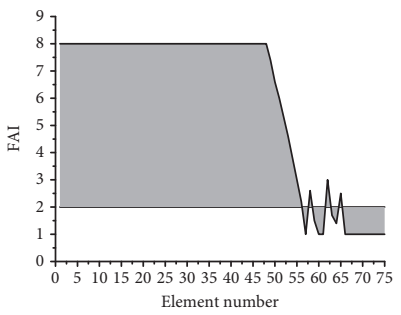

(e)

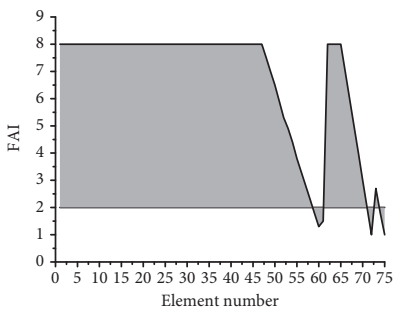

(i)

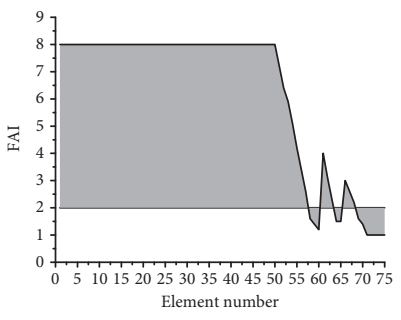

(m)

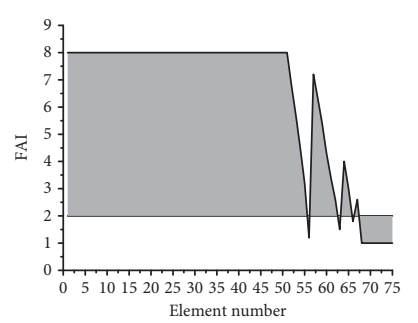

(b)

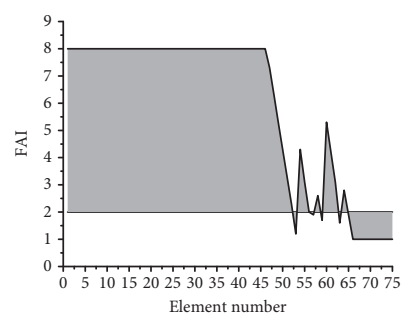

(f)

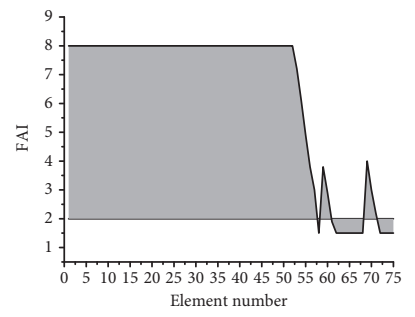

(j)

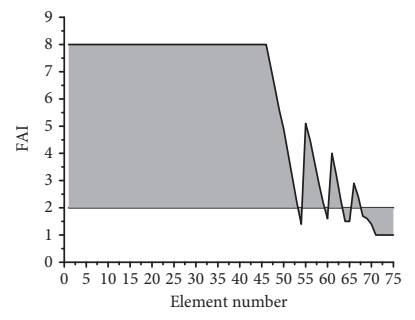

(n)

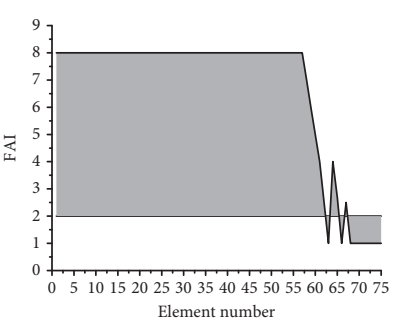

(c)

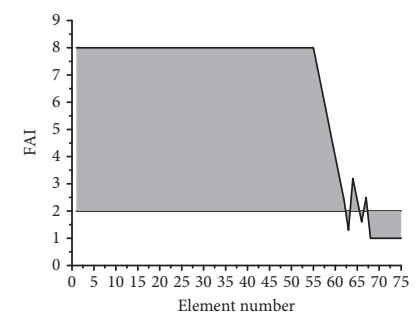

(g)

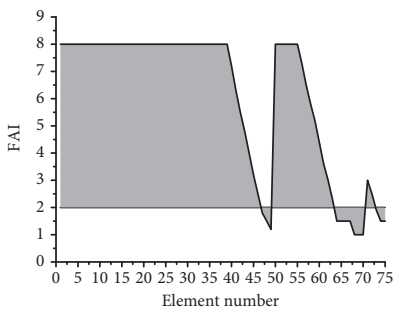

(k)

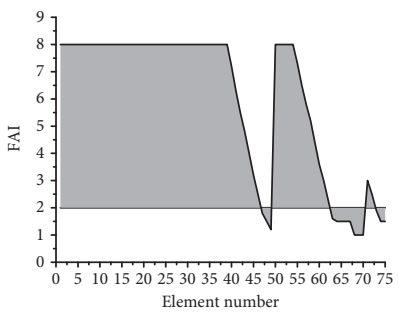

(o)

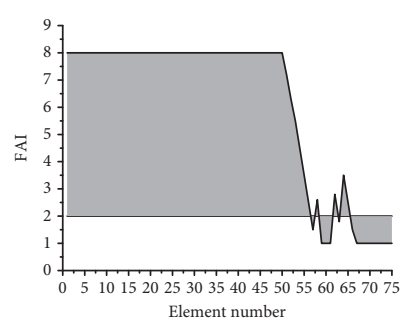

(d)

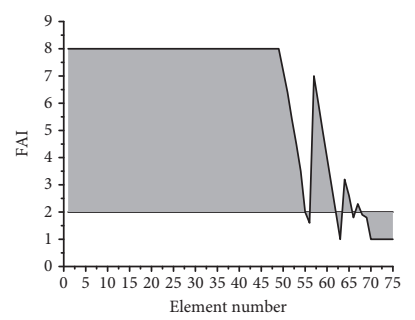

(h)

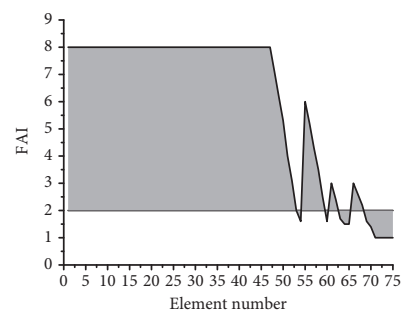

(1)

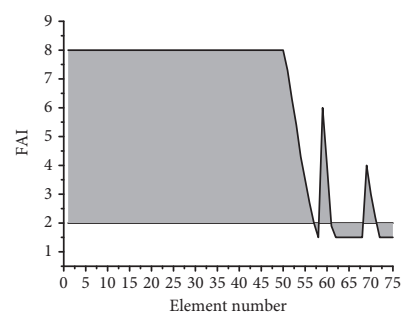

(p)

Figure 16: FAI at each survey line. (a) 1\#. (b) 2\#. (c) 3\#. (d) 4\#. (e) 5\#. (f) 6\#. (g) 7\#. (h) 8\#. (i) 9\#. (j) 10\#. (k) 11\#. (l) 12\#. (m) 13\#. (n) 14\#. (o) 15\#. (p) 16\#.

represents the distance from the fractured zone starting location to the sidewall and External Diameter (ED) represents the distance from the fractured zone ending location to the sidewall along the survey line.

There are four fractured zones based on the Table 3. Based on ID and ED of fractured zones, the scope and location of fractured zones can be obtained. The comparison between numerical simulation and field survey $[5,23]$ is shown in Table 4.

For tunnel top, the number, scope, and location of zonal disintegration using numerical simulation have great agreement with those of field survey. The simulated width of the fourth fractured zone differs greatly from that of field survey. The reason is that the exceptional data point (16.61) in the survey lines $1 \#$ and 9\# has been deleted when the fractured zones are calculated. The widths of four fractured zones are $2.95 \mathrm{~m}, 1.36 \mathrm{~m}, 1.29 \mathrm{~m}$, and $0.06 \mathrm{~m}$, respectively, and the widths of three nonfractured zones are $0.28 \mathrm{~m}, 0.70 \mathrm{~m}$, and $0.64 \mathrm{~m}$, respectively. From the location and width of fractured and nonfractured zones in the survey lines, we draw a sketch map of fractured zones using speculative method as shown in Figure 17(a).

The field survey is only conducted at the top of tunnel. The real zonal disintegrations at the sidewall and bottom are not known. From numerical simulation, the number of fractured zones at the sidewall and bottom is three. The average widths of fractured zones are $5.20 \mathrm{~m}, 2.54 \mathrm{~m}$, and $4.01 \mathrm{~m}$, respectively, and the average width of nonfractured zones is $0.61 \mathrm{~m}$ and $6.65 \mathrm{~m}$. The shape of the third fractured zone is similar to that of the tunnel. 
TABle 3: The distribution of nonfractured zones for different survey lines (units: $\mathrm{m}$ ).

\begin{tabular}{|c|c|c|c|c|c|c|c|c|c|c|c|}
\hline & \multirow{3}{*}{ Survey lines no. } & \multicolumn{10}{|c|}{ Nonfractured zone } \\
\hline & & \multicolumn{2}{|c|}{ The first } & \multicolumn{2}{|c|}{ The second } & \multicolumn{2}{|c|}{ The third } & \multicolumn{2}{|c|}{ The fourth } & \multicolumn{2}{|c|}{ The fifth } \\
\hline & & ID & $\mathrm{ED}$ & ID & $\mathrm{ED}$ & ID & ED & ID & ED & ID & ED \\
\hline \multirow{10}{*}{ Arch section } & $1 \#$ & - & - & - & - & 5.87 & 7.04 & - & - & $/(16.61)$ & - \\
\hline & $2 \#$ & - & - & 5.03 & 5.28 & 7.44 & 7.93 & 9.07 & 9.73 & 10.46 & - \\
\hline & $3 \#$ & - & - & 5.25 & 5.51 & 7.44 & 7.93 & 9.07 & 9.73 & 10.46 & - \\
\hline & $4 \#$ & 5.28 & 5.56 & 5.87 & 6.20 & 7.44 & 7.93 & - & - & 9.07 & - \\
\hline & $5 \#$ & 5.29 & 5.56 & 5.87 & 6.20 & 7.44 & 7.93 & - & - & 9.07 & - \\
\hline & $6 \#$ & 4.39 & 4.59 & 5.87 & 6.20 & 7.44 & 8.48 & - & - & 8.47 & - \\
\hline & 7\# & - & - & 5.22 & 5.46 & 7.44 & 7.93 & 9.09 & 9.70 & 10.46 & - \\
\hline & $8 \#$ & - & - & 5.03 & 5.28 & 7.44 & 7.93 & 9.09 & 9.73 & 10.46 & - \\
\hline & 9\# & - & - & - & - & 5.87 & 6.99 & - & - & $/(16.61)$ & - \\
\hline & Average & 4.99 & 5.24 & 5.45 & 5.73 & 7.09 & 7.79 & 9.08 & 9.72 & 9.78 & - \\
\hline \multirow{8}{*}{ Sidewall and bottom } & $10 \#$ & 0 & - & - & 5.97 & 6.58 & 7.97 & 17.12 & 22.80 & & \\
\hline & $11 \#$ & 0 & - & - & 5.58 & 6.13 & 11.68 & 22.86 & 27.59 & & \\
\hline & $12 \#$ & 0 & 2.92 & 3.22 & 5.25 & 5.72 & 6.86 & 9.13 & 12.13 & & \\
\hline & $13 \#$ & 0 & - & - & 3.18 & 4.24 & 5.65 & 6.84 & 9.11 & & \\
\hline & $14 \#$ & 0 & 2.92 & 3.22 & 5.20 & 5.72 & 7.64 & 9.16 & 11.04 & & \\
\hline & $15 \#$ & 0 & - & - & 5.23 & 5.72 & 10.67 & 22.78 & 27.62 & & \\
\hline & $16 \#$ & 0 & - & - & 5.97 & 6.57 & 7.97 & 17.12 & 22.80 & & \\
\hline & Average & 0 & - & - & 5.20 & 5.81 & 8.35 & 15.00 & 19.01 & & \\
\hline
\end{tabular}

TABLE 4: Comparison between numerical simulation and field measurement (units: $\mathrm{m}$ ).

\begin{tabular}{lcccccc}
\hline \multirow{2}{*}{ Fractured zone } & Actual & Numerical & D-value & \multicolumn{2}{c}{ The width of fractured zone } \\
& measurement & modeling & Actual measurement & Numerical modeling \\
\hline \multirow{2}{*}{ I } & ID & 2.50 & 2.50 & 0 & 2.49 & 2.95 \\
\hline \multirow{2}{*}{ II } & ED & 4.99 & 5.45 & 0.46 & 0.80 & \multirow{2}{*}{1.36} \\
& ID & 5.75 & 5.73 & -0.02 & \multirow{2}{*}{1.04} & \multirow{2}{*}{1.29} \\
\multirow{2}{*}{ III } & ED & 6.55 & 7.09 & 0.54 & 0.53 & 0.06 \\
\hline \multirow{2}{*}{ IV } & ID & 7.74 & 7.79 & 0.05 & 0.30 \\
\hline
\end{tabular}

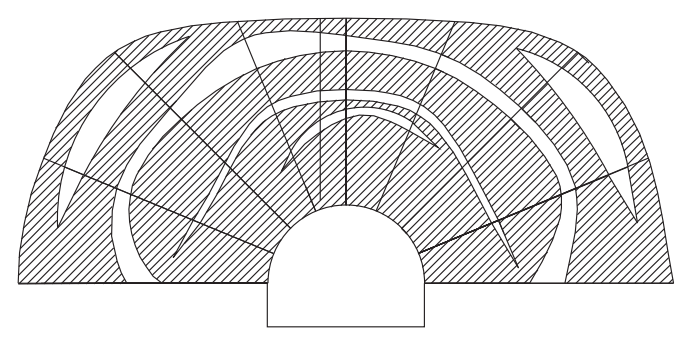

WIIA Failure zone

Non-failure zone

(a)

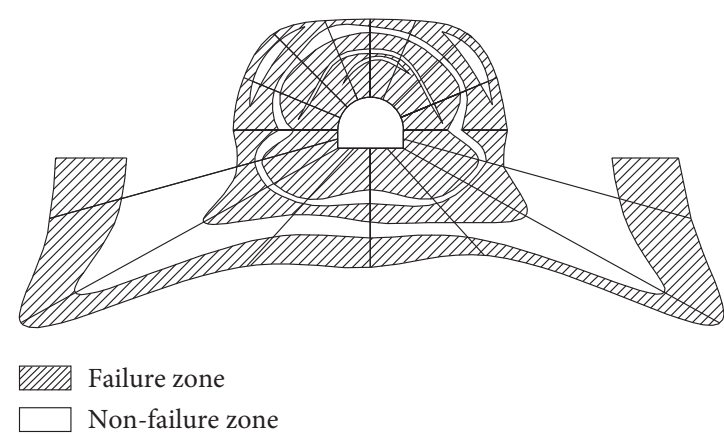

(b)

FIgURE 17: Fractured zones from numerical simulation. (a) Top section of tunnel. (b) Sidewall and bottom of tunnel.

\section{Conclusions}

Strain softening Mohr-Coulomb Model is appropriate for zonal disintegration simulation. The FAI can be used to represent the rock failure. The location and scope of nonfractured and fractured zones can be obtained from FAI through simulation. High axial stress is necessary for zonal disintegration generation. The precondition for zonal disintegration generation is that tensile failure happens in the PSZ zone. The width of fractured zone caused by fast unloading is bigger than that of slow unloading. Only when the axial stress is more than the uniaxial compressive 
strength, zonal disintegration appears. The width of fractured zone increases with the tunnel radius. For the arch rectangular tunnel, there is no zonal disintegration at the sidewall. The shape of zonal disintegration is similar to the shape of the tunnel. With a mine in China as an example, we demonstrated the validity of our numerical approach for zonal disintegration simulation.

\section{Data Availability}

In order to verify the results of this article, replicate the analysis, and conduct secondary analyses, for any reader or researcher who wishes to obtain the research data of this article, please contact the corresponding author via jinliu920@163.com.

\section{Conflicts of Interest}

The authors declare that there are no conflicts of interest regarding the publication of this paper.

\section{Acknowledgments}

This research was financially supported by the Natural Science Foundation of China (Grant nos. 41672258 and 41472241). The authors gratefully acknowledge M. S. Changfei Zhang in School of Earth Sciences and Engineering, Hohai University, China, for his contribution to the numerical simulation.

\section{References}

[1] H.-S. Guo, X.-T. Feng, S.-J. Li, C.-X. Yang, and Z.-B. Yao, "Evaluation of the integrity of deep rock masses using results of digital borehole televiewers," Rock Mechanics and Rock Engineering, vol. 50, no. 6, pp. 1371-1382, 2017.

[2] M. Wang, J. Li, L. Ma, and H. Huang, "Study on the characteristic energy factor of the deep rock mass under weak disturbance," Rock Mechanics and Rock Engineering, vol. 49, no. 8, pp. 3165-3173, 2016.

[3] X. P. Zhou, F. H. Wang, Q. H. Qian, and B. H. Zhang, "Zonal fracturing mechanism in deep crack-weakened rock masses," Theoretical and Applied Fracture Mechanics, vol. 50, no. 1, pp. 57-65, 2008.

[4] X. L. Jiang, F. F. Wang, H. Yang, and J. Y. Niu, "Parameter sensitivity of shallow-bias tunnel with a clear distance located in rock," Advances in Civil Engineering, vol. 2018, Article ID 5791354, 11 pages, 2018.

[5] X.-G. Chen, Y. Wang, Q.-Y. Zhang, S.-C. Li, and E. Nordlund, "Analogical model test and theoretical analysis on zonal disintegration based on filed monitoring in deep tunnel," European Journal of Environmental and Civil Engineering, vol. 17, no. 1, pp. s33-s52, 2013.

[6] Y. Zuo, T. Xu, Y. Zhang et al., "Numerical study of zonal disintegration within a rock mass around a deep excavated tunnel," International Journal of Geomechanics, vol. 12, no. 4, pp. 471-483, 2012.

[7] X. Zhou, Q. Qian, and B. Zhang, "Zonal disintegration mechanism of deep crack-weakened rock masses under dynamic unloading," Acta Mechanica Solida Sinica, vol. 22, no. 3, pp. 240-250, 2009.
[8] X. Chen, Y. Wang, Y. Mei, and X. Zhang, "Numerical simulation on zonal disintegration in deep surrounding rock mass," The Scientific World Journal, vol. 2014, Article ID 379326, 8 pages, 2014.

[9] P. Jia and W. C. Zhu, "Mechanism of zonal disintegration around deep underground excavations under triaxial stress-insight from numerical test," Tunnelling and Underground Space Technology, vol. 48, pp. 1-10, 2015.

[10] Q. Zhang, X. Zhang, Z. Wang, W. Xiang, and J. Xue, "Failure mechanism and numerical simulation of zonal disintegration around a deep tunnel under high stress," International Journal of Rock Mechanics and Mining Sciences, vol. 93, pp. 344-355, 2017.

[11] E. I. Shemyakin, M. V. Kurlenya, V. N. Oparin et al., "Zonal disintegration of rocks around underground workings. IV. practical applications," Journal of Mining Science, vol. 25, no. 4, pp. 297-302, 1989.

[12] G. D. Adams and A. J. Jager, "Etroscopic observations of rock fracturing ahead of the stope faces in deep-level gold mines," Journal of the South African Institute of Mining and Metallurgy, vol. 21, no. 2, pp. 115-127, 1980.

[13] D. F. Malan and S. M. Spottiswoode, Time-dependent Fracture Zone Behavior and Seismicity Surrounding Deep Level Stopping Operations, A. A. Balkema Publishers, Leiden, Netherlands, 1997.

[14] L. S. Metlov, A. F. Morozov, and M. P. Zborshchik, "Physical foundations of mechanism of zonal rock failure in the vicinity of mine working," Journal of Mining Science, vol. 38, no. 2, pp. 150-155, 2002.

[15] S. C. Li, H. P. Wang, Q. H. Qian et al., "In-situ monitoring research on zonal disintegration of surrounding rock mass in deep mine roadways," Chinese Journal of Rock Mechanics \& Engineering, vol. 27, no. 8, pp. 1545-1553, 2008.

[16] Z. L. Fang, "Support principles for roadway in soft rock and its controlling measures," in Soft Rock Tunnel Support in Chinese Mines: Theory and Practice, M. C. He, Ed., pp. 64-70, China Coal Industry Publishing House, Beijing, China, 1996.

[17] E. J. Sellers and P. Klerck, "Modeling of the effect of discontinuities on the extent of the fracture zone surrounding deep tunnels," Tunneling and Underground Space Technology, vol. 15, no. 4, pp. 463-469, 2000.

[18] J. C. Gu, L. Y. Gu, A. M. Chen, J. Xu, and W. Chen, "Model test study on mechanism of layered fracture within surrounding rock of tunnel in deep stratum," Chinese Journal of Rock Mechanics and Engineering, vol. 27, no. 3, pp. 433-438, 2008.

[19] Q.-H. Qian, “The characteristic scientific phenomena of engineering response to deep rock mass and the implication of deepness," Journal of East China Institute of Technology, vol. 27, no. 1, pp. 1-5, 2004.

[20] M. Wang, H. Song, D. Zheng, and S. Chen, "On mechanism of zonal disintegration within rock mass around deep tunnel and definition of "deep rock engineering," Chinese Journal of Rock Mechanics and Engineering, vol. 25, no. 9, pp. 1771-1776, 2006.

[21] X. G. Chen, T. B. Li, J. P. Xu et al., "Mechanism of zonal disintegration phenomenon and model test validation," Theoretical and Applied Fracture Mechanics, vol. 88, pp. 3950, 2017.

[22] H. Zhou, C. Q. Zhang, X.-T. Feng, and Z.-L. Ru, "Analysis of rock mass stability in tunnel and underground engineering based on yield approach index," Chinese Journal of Rock Mechanics and Engineering, vol. 24, no. 17, pp. 3083-3087, 2005. 
[23] C. Q. Zhang, H. Zhou, and X.-T. Feng, "Stability assessment of rockmass engineering based on failure approach index," Rock and Soil Mechanics, vol. 28, no. 5, pp. 888-894, 2007.

[24] B. Lin, The Study on Geomechanics Model Test of Zone Disintegration in Deep Tunnel of High Ground stress, Shandong University, Jinan, China, 2009. 